\title{
RECRUTAMENTO E SELEÇÃO: ESTUDO DE UM MODELO EFICIENTE
}

\author{
Sandra Mara Bragagnolo \\ https://orcid.org/0000-0002-1001-8541 \\ Adrieli Cordeiro \\ https://orcid.org/0000-0002-9943-8760 \\ Rosangela Tortato Narloch ${ }^{3}$ \\ https://orcid.org/0000-0002-4845-0620 \\ Rodrigo Regert ${ }^{4}$ \\ https://orcid.org/0000-0001-6416-0044
}

Recebido em: 28 set. 2020

Aceito em: 19 out. 2020

Como citar este artigo: BRAGAGNOLO, S. M. .; CORDEIRO, A. .; NARLOCH, R. T. .; REGERT, R. RECRUTAMENTO E SELEÇÃO: ESTUDO DE UM MODELO EFICIENTE: RECRUITMENT AND SELECTION: STUDY OF AN EFFICIENT MODEL . Revista Visão: Gestão Organizacional, Caçador (SC), Brasil, v. 9, n. 2, p. 102-121, 2020. DOI: 10.33362/visao.v9i2.2384. Disponível em: https://periodicos.uniarp.edu.br/index.php/visao/article/view/2384.

Resumo: O presente artigo é resultado de um estudo que teve como objetivo analisar as práticas e políticas de recrutamento e seleção de uma empresa de grande porte localizada na região meio-oeste catarinense, com vistas a avaliar seu modelo de gestão nessa área. Para isso, foram identificadas as diretrizes e ferramentas adotadas pela empresa. Em seguida, fez-se a análise dos dados coletados com a aplicação de um questionário junto a 90 colaboradores da área de produção; e de entrevista semiestruturada com três supervisores e com a gestora do setor na empresa. Esse trabalho foi desenvolvido no mês de setembro de 2017. Utilizou-se de análise qualitativa, descritiva e exploratória. Os resultados apontam para o reconhecimento de que o modelo adotado pela empresa é eficiente. As pessoas que o conduzem têm segurança de seus objetivos. As diretrizes, políticas e técnicas de recrutamento e seleção adotadas são bem-sucedidas e os colaboradores reconhecem sua validade e compreendem o processo a que se submetem para fazer parte do quadro funcional e para crescerem profissionalmente dentro da empresa.

Palavras-Chave: Gestão de pessoas. Recrutamento e seleção. Modelos de Gestão.

RECRUITMENT AND SELECTION: STUDY OF AN EFFICIENT MODEL

Abstract: This article is the result of a study that aimed to analyze the practices and policies of recruitment and selection of a large-sized company located in the Midwest of

\footnotetext{
${ }^{1}$ Mestra em Desenvolvimento e Sociedade. Universidade Alto Vale do Rio do Peixe (UNIARP) - Brasil. Email: sandramara@uniarp.edu.br

2 Bacharel em Administração. Universidade Alto Vale do Rio do Peixe (UNIARP) - Brasil. Email: adrielicordeiro620@gmail.com

${ }^{3}$ Especialista em Administração de Recursos Humanos. Fundação Universidade do Contestado (UNC) - Brasil. Email: rtnarloch@gmail.com

${ }^{4}$ Mestre em Desenvolvimento e Sociedade. Universidade Alto Vale do Rio do Peixe (UNIARP) - Brasil. Email: regert.rodrigo@gmail.com
} 
Santa Catarina, with the aim of evaluating its management model in this area. For this, the guidelines and tools adopted by the company were identified. Then, the data collected were analyzed with the application of a questionnaire to 90 employees of the production area; and a semi-structured interview with three supervisors and with the manager of the sector in the company. This work was developed in September 2017. Qualitative, descriptive and exploratory analysis were used. The results point to the recognition that the model adopted by the company is efficient. The people who lead it are sure of its goals. Recruitment and selection guidelines, policies and techniques are successful and employees recognize their validity and understand the process they undergo to become part of the staff and to grow professionally within the company.

Keywords: People management. Recruitment and selection. Management Models.

\section{INTRODUÇÃO}

Os processos de recrutamento e seleção de pessoas se tornam cada vez mais importantes, uma vez que constituem ferramentas através das quais é possível identificar a capacidade e qualificação dos colaboradores. Esse artigo tem foco no processo de recrutamento e seleção dos colaboradores de uma empresa de grande porte situada em Fraiburgo, região meio-oeste de Santa Catarina.

A realização desse estudo partiu da constatação de que o modelo adotado pela empresa em estudo seria uma referência em recrutamento e seleção. Assim, buscou-se analisar como gestores e colaboradores reconhecem o processo que a empresa aplica e quais seus resultados. Assim, a questão norteadora desse estudo investigou o nível de conhecimento das rotinas de recrutamento e seleção por parte dos colaboradores da área de produção, as percepções de seus supervisores, bem como os procedimentos conduzidos pela gestão do setor de Recursos Humanos - RH da empresa, de modo a evidenciar o nível de excelência do método adotado.

\section{GESTÃO DE PESSOAS}

A gestão de pessoas é muito importante nas organizações, pois se tornou estratégica para o alcance dos objetivos organizacionais, passando a assumir papel de liderança para alcançar a excelência necessária para enfrentar desafios competitivos, tais como a globalização, a utilização das novas tecnologias e a gestão do capital intelectual (GIL, 2007, p. 60).

Não há como promover a gestão de pessoas se não houver um planejamento estratégico. Segundo Bohlander e Snell (2010, p. 37), as pessoas sempre foram fundamentais para as organizações, e sua importância estratégica está crescendo nas indústrias atuais, que têm o conhecimento como base.

Cada vez mais, o sucesso de uma organização depende do conhecimento, das 
capacidades e das habilidades de seus colaboradores. A Gestão de Pessoas é"a função gerencial que visa à cooperação das pessoas que atuam nas organizações para o alcance dos objetivos tanto organizacionais quanto individuais" (GIL, 2001, p. 17).

Conforme Ribeiro (2005, p. 13), a gestão de pessoas é responsável por ações como recrutamento, seleção, treinamento, planos de cargos e salários, contratação, remuneração e questões trabalhistas. Contudo, para uma atuação estratégica, deve ainda adotar medidas para desenvolver talentos e criar um ambiente de trabalho aberto a novas ideias.

O desempenho das organizações depende da contribuição das pessoas que a compõem, da forma como está organizada e também do investimento que é realizado ao nível do seu desenvolvimento (SOUSA et al, 2014).

Para Tachizawa, Ferreira e Fortuna (2001 p. 232), cuidar das pessoas "constitui, pois, um dos fatores decisivos para o aumento da produtividade, na medida em que reduz o número de faltas decorrentes de condições de trabalho inadequadas". Os autores concluem que "deixar de investir nessa área é uma desconsideração para com os funcionários e pode comprometer até mesmo a imagem da empresa" (TACHIZAWA; FERREIRA; FORTUNA, 2001 p. 234).

\section{RECRUTAMENTO DE PESSOAS}

O recrutamento visa a captar talentos para a organização, sendo o processo inicial para se preencherem requisitos necessários quando há uma vaga aberta. Assim, trata-se de um conjunto de técnicas e procedimentos para atrair candidatos potencialmente qualificados e capazes de ocupar cargos. Segundo Ribeiro (2005, p. 52), "trata-se de um trabalho de pesquisa junto às fontes capazes de oferecer à organização um número suficiente de pessoas".

"O processo começa quando são procurados novos recrutas e termina quando são apresentados os formulários de solicitação de emprego" (WERTHER; DAVIS, 1983, p. 145). Um bom recrutamento demanda de um bom planejamento, pois "esperar para encontrar pessoas capacitadas para preencher as vagas da organização pode levar a demoras desnecessárias e escolhas precipitadas. Isso não acontecerá se houver planejamento de pessoal".

Segundo Bohlander e Snell (2010, p. 158), “o recrutamento é o processo de localizar indivíduos em potencial que possam trabalhar para uma organização e encorajá-las a se candidatar a vagas já existentes ou então antes que elas sejam abertas". É nesse momento que o setor de recursos humanos repassa as informações e benefícios, os quais visam manter os candidatos interessados.

"O recrutamento de pessoal constitui uma sistemática que objetiva atrair candidatos diretamente nas fontes de recrutamento sendo elas internas ou externas" (TACHIZAWA; FERREIRA; FORTUNA, 2001, p. 168). Nas organizações são realizados três tipos de recrutamento: externo, interno e misto. 


\section{RECRUTAMENTO INTERNO, EXTERNO E MISTO}

O recrutamento interno visa promover novos talentos de dentro da organização. Para Pontes (2004, p. 85), "recrutamento interno é o preenchimento das vagas por meio da promoção ou transferência de funcionários da organização. É a valorização dos recursos humanos internos". O recrutamento interno exige uma intensa e contínua coordenação bem como a integração do gestor de pessoas com os demais setores da organização.

"Quando as organizações optam pelo recrutamento interno, cometendo justiça no processo, ou seja, escolhendo profissionais capazes e com bons desempenhos, estimula os demais na busca da excelência" (PONTES, 2004, p. 10). É o reconhecimento que a companhia faz aos colaboradores que estão aprimorando seus conhecimentos, aumentando suas capacitações e desempenhando bem suas atividades. As promoções internas recompensam os funcionários pelo seu desempenho e os incentivam a continuarem com seus esforços, estimulando os demais a adotarem as mesmas atitudes, melhorando, portanto, o ânimo interno da organização (BOHLANDER; SNELL, 2010).

O recrutamento externo ocorre quando a empresa busca candidatos em fontes externas, ou seja, ocorre quando há uma vaga num determinado setor e a organização procura preenchê-la com candidatos externos à organização (SOUSA et al., 2014). A busca por candidatos externos dá-se por: consulta aos arquivos de candidatos, apresentação de candidatos por parte de funcionários já existentes da empresa; cartazes ou anúncios na portaria da empresa; contatos com sindicatos e associações de classe; anúncios em jornais e revistas e em agência de recrutamento. O recrutamento externo tem vantagens, principalmente no tocante à renovação de ideias (PONTES, 2004, p. 109).

O recrutamento misto é a combinação do recrutamento interno e externo. Existem três possibilidades de proceder ao recrutamento de forma mista, que são: "Começando pelo recrutamento externo, passando para o recrutamento interno; começando pelo recrutamento interno, passando para o recrutamento externo; começando pelos recrutamentos interno e externo, simultaneamente" (ARAUJO, 2006, p. 34).

\section{SELEÇÃO DE PESSOAS}

A seleção de pessoal é a escolha de candidatos que se destacam, sendo os mais adequados para a organização. Acontece após as pessoas serem recrutadas. É a escolha do candidato certo. Segundo Bohlander e Snell (2010, p. 209), "na maioria das organizações, a seleção é um processo contínuo. A rotatividade ocorre inevitavelmente, deixando vagas a serem preenchidas por candidatos da organização e fora dela, ou pelos indivíduos cujas qualificações foram validadas anteriormente".

De acordo com Pontes (2004, p. 130), "o processo de seleção inicia-se geralmente por 
uma triagem entre os candidatos recrutados. Esta normalmente é realizada por entrevista rápida e análise do currículo ou ficha de inscrição do candidato". Seleção é o processo de escolher o melhor candidato para o cargo, preenchendo os critérios para a vaga disponível.

Para Marras (2002, p. 79), o processo de seleção de pessoal baseia-se fundamentalmente na análise comparativa de dois itens que são: Especificação de cargo - o que o cargo requer - variável obtida através da Análise e Descrição de cargo para saber quais requisitos o cargo exige de seu ocupante e; Características do candidato - o que o candidato oferece - variável obtida através da aplicação de técnicas de seleção para saber quais as condições pessoais para ocupar o cargo.

"Para que se possa selecionar adequadamente, torna-se necessário definir critérios. Para tanto, requer-se o conhecimento das políticas de seleção da empresa e sobretudo dos cargos que se deseja preencher" (GIL, 2014, p. 92). Primeiramente, é feito o recrutamento; após, são selecionados os melhores.

As técnicas de seleção, segundo Tachizawa, Ferreira e Fortuna (2001, p. 172), "variam em função da estratégia adotada pela organização, dos aspectos conjunturais do mercado, e das características da mão de obra a ser selecionada". As técnicas de seleção de pessoal mudam, portanto, "conforme o nível ocupado pelo cargo na hierarquia da estrutura organizacional, nível que normalmente é preestabelecido na descrição e especificação do cargo" (TACHIZAWA; FERREIRA; FORTUNA, 2001, p. 171).

Uma das primeiras etapas é a entrevista. Para Gil (2014, p. 101), "a entrevista distingue-se de uma simples conversação à medida que serve a um objeto definido, é sistematicamente planejada e submetida a controles de avaliação". Gil (2014, p. 100) ainda recomenda "a utilização de testes escritos para o preenchimento de cargos, para os quais se requerem conhecimentos específicos, bem como determinadas habilidades, como, por exemplo, a de redação".

Testes psicológicos são instrumentos muito úteis para identificar as aptidões dos candidatos. Podem ser utilizados para a avaliação do potencial intelectual dos candidatos, de suas habilidades específicas. Também existe a prática de dinâmicas, conhecidas também como técnicas de simulação, que procuram colocar o candidato em situações grupais de interação social.

\section{GESTÃO ESTRATÉGICA EM GESTÃO DE PESSOAS}

A estratégia organizacional refere-se ao comportamento global e integrado da organização em relação ao ambiente em que se insere. Normalmente, a estratégia está relacionada à mudança organizada. De acordo com Gil (2001, p. 34), "uma empresa que procura criar capacidade organizacional global precisa identificar se seus recursos humanos 
estão preparados para enfrentar o desafio das mudanças propostas".

Segundo Tachizawa, Ferreira e Fortuna, (2001 p. 58), "o plano estratégico de gestão de pessoas é elaborado a partir das diretrizes emanadas do plano estratégico [...], o planejamento da empresa tem por fim desenvolver e implementar estratégias gerenciais de recursos humanos".

"A função de recursos humanos assume papel relevante na definição das estratégias do negócio e definem-se políticas e práticas mais modernas, adequadas ao processo de atrair, reter e desenvolver os melhores talentos" (FLEURY, 2013, p. 80).

"Um dos indicadores de desempenho empresarial, talvez o mais importante no atual contexto de mercado, é sua capacidade de atrair, desenvolver e reter pessoas talentosas" (GRAMIGNA, 2002, p. 11). Dois grandes desafios se colocam para as organizações em termos de desenvolvimento de um modelo de gestão: "alinhar realmente as competências individuais às competências organizacionais e às estratégias de negócio das empresas; desenvolver nas pessoas competências que não apenas agreguem valor à organização, mas que também agreguem valor ao indivíduo" (FLEURY, 2013, p. 84).

Acredita-se que a busca pela competência essencial deve ser acompanhada pelo investimento naquelas que constituem a base interna dos processos empresariais (GRAMIGNA, 2002, p. 54). O conceito de competência é pensado como um conjunto de conhecimentos, habilidades e atitudes que justificam um alto desempenho, na medida em que há um pressuposto de que os melhores desempenhos estão fundamentados na inteligência e na personalidade das pessoas; nessa abordagem, considera-se a competência, portanto, um estoque de recursos que o indivíduo detém (FLEURY, 2013, p. 28).

O conceito de competência organizacional tem suas raízes na abordagem da organização como um portfólio de recursos. Essa abordagem considera que toda empresa tem um portfólio: físico, financeiro, intangível, organizacional e recursos humanos (FLEURY, 2013, p. 32). O fenômeno da inovação apresenta características inusitadas: não pode ser tocado, ouvido ou provado. Porém, quando acontece, é sentido, pensado e percebido (GRAMIGNA, 2002, p. 3).

\section{MATERIAL E MÉTODOS}

A pesquisa teve foco no processo de recrutamento e seleção de colaboradores para uma empresa de grande porte situada na cidade de Fraiburgo, região meio-oeste de Santa Catarina. Trata-se, pois, de um estudo de caso de natureza qualitativa, ou seja, busca descrever a realidade, interpretando seus aspectos, sob uma abordagem descritiva e exploratória.

A empresa em estudo teve sua fundação em 1941 e se transformou em grupo industrial a partir de 1971. Modernizou-se constantemente, para ser cada vez mais competitiva 
e competente no atendimento às demandas do mercado. É uma das principais do segmento de embalagens de papel do Brasil e da América Latina. É a segunda maior produtora de sacos de papel multifoliados do Brasil e a quarta de embalagens de papelão ondulado, além de ser uma das maiores recicladoras de papel para embalagens do país. Ainda, desenvolve amplas florestas de pinus e de eucaliptos, planejadas para serem colhidas e replantadas, complementando sua sustentabilidade (TROMBINI, web).

A empresa conta com aproximadamente 500 colaboradores. Destes, 100 trabalham na área de produção em que este estudo foi desenvolvido; e 90 responderam a essa pesquisa. 0 universo, portanto, é composto por 90 colaboradores, os quais responderam a um questionário, composto por 22 questões, sendo 21 objetivas e uma descritiva. Com isso, buscou-se identificar as percepções dos colaboradores acerca do processo de recrutamento e seleção a que foram submetidos. A pesquisa foi realizada no mês de setembro de 2017.

Também se aplicou uma entrevista semiestruturada com 12 questões junto aos supervisores desses 90 colaboradores da organização e foi realizada entrevista com 23 questões descritivas junto à gestora de Recursos Humanos da empresa cedente.

Os dados coletados foram tabulados em quadros e gráficos e foi utilizada, para parametrização, a Escala de Lickert, que, segundo Marconi e Lakatos (2011, p. 109), "idealizou um método mais simples de construir escalas de atitudes, que não requer especialista". A escala de Lickert utilizada apresentou cinco proposições: ótimo, bom, indiferente, ruim e péssimo.

\section{RESULTADOS}

Segundo a gestora de RH da empresa em estudo, adota-se aí uma ação estratégica para cuidar das pessoas, sendo que os salários são pagos em valor acima da média na cidade e os benefícios, como plano de saúde e plano odontológico, são bons motivos para as pessoas permanecerem na empresa.

A área de RH/Gestão de Pessoas, na empresa em estudo, presta assessoria às demais áreas, com função de staff. Está ligada diretamente à gerência e às ações que a empresa toma com relação às pessoas. Currículos de possíveis candidatos são recebidos no setor ou, caso o candidato não o tenha, preenche uma ficha na recepção da empresa. A veracidade das informações contidas no currículo é confirmada na avaliação dos candidatos quando selecionados para entrevista.

Quando há a abertura de vaga, é montado um perfil de competências para o cargo, sendo esse perfil o profissiográfico, que orienta sobre o perfil psicológico e a exigência de formação necessária para cada vaga. A média de tempo de duração do processo gira em torno de 30 a 45 dias, conforme a vaga. A empresa se utiliza de um fluxograma com fases, 
apresentado no Quadro 1, pelas quais o candidato passa desde a entrega do currículo até assumir efetivamente o cargo.

Quadro 1 - Fluxograma do Processo Seletivo

\begin{tabular}{|c|c|c|c|}
\hline AÇÃO & PROCEDIMENTO & ATRIBUIÇÃO & REGISTRO \\
\hline $\begin{array}{l}\text { Emitir RP (Requisição } \\
\text { de Pessoal) no portal } \\
\text { RH }\end{array}$ & $\begin{array}{l}\text { Na emissão da RP, consideram-se: } \\
\text { Requisitos especificados no perfil } \\
\text { profissiográfico. }\end{array}$ & Liderança & Portal RH \\
\hline Divulgar a vaga & $\begin{array}{l}\text { Informar em edital: local e data de } \\
\text { inscrição, requisitos e perfil da vaga } \\
\text { existente, devendo o edital de inscrição } \\
\text { permanecer aberto por no mínimo } \\
\text { cinco dias. }\end{array}$ & Requisitante & Portal RH \\
\hline $\begin{array}{l}\text { Inscrição dos } \\
\text { candidatos } \\
\text { internos/externo }\end{array}$ & $\begin{array}{l}\text { Preencher o formulário de inscrição e } \\
\text { apanhar aprovação e assinatura da } \\
\text { liderança do setor quando candidatos } \\
\text { internos. }\end{array}$ & Colaborador & $\begin{array}{l}\text { FOR USC.RH.01 } \\
\text { (Formulário - } \\
\text { Unidade Santa } \\
\text { Catarina - RH) }\end{array}$ \\
\hline Processo seletivo & $\begin{array}{l}\text { Analisar se o candidato atende os } \\
\text { requisitos requeridos, avaliar histórico } \\
\text { do candidato, assinar formulário de } \\
\text { inscrição. }\end{array}$ & Liderança & $\begin{array}{l}\text { Sistema de } \\
\text { Informação da } \\
\text { Empresa }\end{array}$ \\
\hline Seleção & $\begin{array}{l}\text { Utilizar técnicas de seleção conforme } \\
\text { perfil do cargo em aberto: testes de } \\
\text { escolaridade, técnicos, psicológicos, } \\
\text { provas situacionais, dinâmica de grupo, } \\
\text { entrevista e outros para avaliar } \\
\text { candidatos. } \\
\text { Escolher, através do resultado do } \\
\text { processo seletivo, o candidato mais } \\
\text { adequado para a vaga. }\end{array}$ & RH e liderança & $\begin{array}{l}\text { Sistema de } \\
\text { Informação da } \\
\text { Empresa }\end{array}$ \\
\hline Divulgar resultado & $\begin{array}{l}\text { Após divulgação do candidato } \\
\text { selecionado, emitir formulário e } \\
\text { encaminhar o candidato para o } \mathrm{RH}\end{array}$ & $\mathrm{RH}$ & $\begin{array}{l}\text { Sistema de } \\
\text { Informação da } \\
\text { Empresa }\end{array}$ \\
\hline $\begin{array}{l}\text { Emitir AR (Alteração } \\
\text { de Registro) e } \\
\text { encaminhar para } \\
\text { exames }\end{array}$ & $\begin{array}{l}\text { Encaminhar o colaborador selecionado } \\
\text { internamente para o ambulatório, para } \\
\text { realizar exame de mudança de } \\
\text { cargo/função. Quando externo, para } \\
\text { exame admissional. }\end{array}$ & $\begin{array}{l}\text { RH e médico do } \\
\text { trabalho }\end{array}$ & $\begin{array}{l}\text { (Formulário Unidade } \\
\text { Santa Catarina } \\
\text { Recursos Humano) } \\
\text { FOR USC.RH.07 e } \\
\text { Prontuário Médico }\end{array}$ \\
\hline Avaliação & $\begin{array}{l}\text { Emitir formulário de alteração de } \\
\text { registro e encaminhar o candidato para } \\
\text { o RH; } \\
\text { Quando candidatos externos, } \\
\text { encaminhar para consulta admissional } \\
\text { e registro. }\end{array}$ & Liderança & FOR USC.RH.07 \\
\hline $\begin{array}{l}\text { Quando candidato } \\
\text { interno passa por } \\
\text { mudança de } \\
\text { cargo/função }\end{array}$ & $\begin{array}{l}\text { Verificar, através de exame médico, se } \\
\text { o candidato está apto para o novo } \\
\text { cargo e dar retorno ao mesmo; } \\
\text { Efetivar no cargo e função. }\end{array}$ & $\mathrm{RH}$ & $\begin{array}{l}\text { Sistema de } \\
\text { Informação da } \\
\text { Empresa }\end{array}$ \\
\hline
\end{tabular}

Fonte: Empresa cedente (2017). 
De acordo com a gestora de $\mathrm{RH}$, a rotatividade encontra-se abaixo de $1 \%$. Os critérios utilizados pela empresa para a escolha dos candidatos a vagas são: escolaridade, experiência e perfil conforme o exigido e avaliado para cada cargo. Já as técnicas utilizadas para recrutamento e seleção são: provas técnicas e de conhecimentos gerais, testes e avaliação psicológicos, entrevistas e dinâmicas. O principal desafio, de acordo com a gestora, é acertar o perfil adequado para cada vaga. As provas aplicadas são elaboradas e corrigidas em conjunto com o supervisor de área.

Considerando a hipótese de haver candidatos satisfatórios em quantidade superior ao número de vagas, são considerados detalhes mínimos avaliados em cada um e conforme cada caso e cargo. Porém, prevalece, na hora da contratação, o melhor desempenho durante a entrevista, pois não basta um bom currículo se o candidato não tiver perfil adequado ao cargo e função que irá desempenhar.

No que se refere à tendência nas ações do processo de recrutamento e seleção, a empresa utiliza um modelo de gestão participativa. Valoriza e dá oportunidade aos colaboradores, visando reter e fidelizar a mão de obra. O setor de $\mathrm{RH}$, juntamente com supervisores de área, trabalha com gestão de conflitos, buscando evitá-los. Essas ações geram um ambiente sadio e de boa relação entre colaboradores e gestores.

Ao analisar as respostas obtidas junto aos 90 colaboradores da área de produção e com os três supervisores de produção, buscou-se conhecer as percepções e níveis de satisfação deles quanto ao processo de recrutamento e seleção a que foram submetidos. Em relação ao perfil dos respondentes, coletaram-se as seguintes informações: gênero, faixa etária, tempo de empresa, cargo ou função, tempo no cargo/função, nível de escolaridade, se possui curso técnico, se foi a empresa quem oportunizou, e remuneração mensal.

Quanto ao gênero, observa-se que, para a área em pesquisa, há preferência pelo gênero masculino devido à natureza do trabalho, que exige emprego de força física. Assim, 99\% dos entrevistados é do gênero masculino; e apenas $1 \%$ do gênero feminino.

A organização apresenta equilíbrio de idade entre os colaboradores: $30 \%$, com 20 a 30 anos; 33\%, com 31 a 40 anos; 26\%, com 41 a 50 anos; e 11\% com idade acima de 50 anos. Aqui, confirma-se o que a assessora informou sobre os programas de retenção e fidelização da mão de obra. Os mais jovens estão há menos tempo na empresa. A contratação de jovens renova e mantém o quadro. Os com mais idade também possuem mais tempo de empresa, conforme o gráfico 1. 
Gráfico 1 - Tempo de empresa

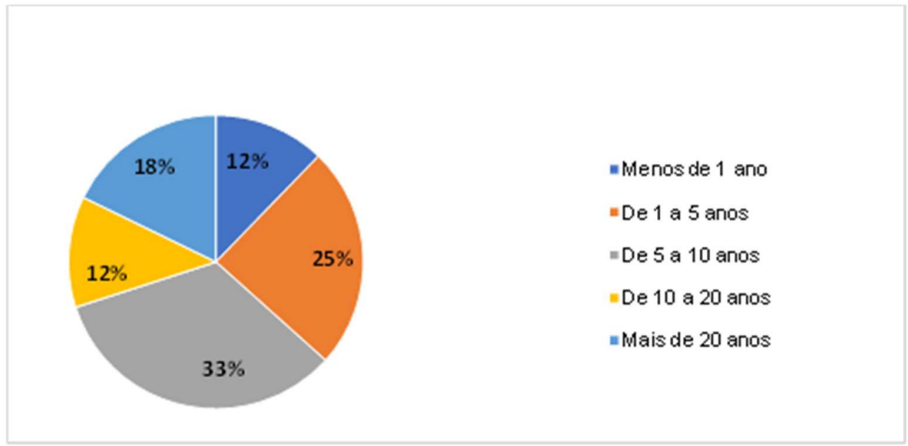

Fonte: Dados da pesquisa (2017)

Pode-se verificar que a empresa retém pessoas, pois a maioria está na empresa há mais de cinco anos, se comparado ao gráfico 2, percebe-se uma progressão na carreira dos colaboradores que estão há mais tempo. Os colaboradores com mais de 20 anos (18\%) ingressaram na empresa na função I e, conforme seu desenvolvimento profissional e promoções oferecidas pela empresa, foram crescendo gradualmente, na escala de I a V.

Gráfico 2 - Cargo ou Função exercida no setor de produção

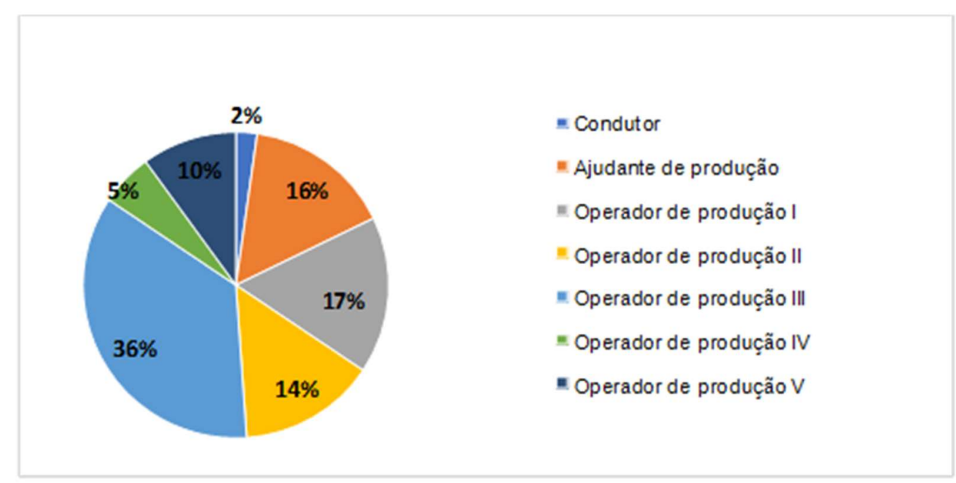

Fonte: Dados da pesquisa (2017)

Observa-se que os operadores de produção evoluem em funções na escala de I a V, conforme suas habilidades, desenvolvimento e tempo de empresa, como também oportuniza a troca de função. Essa atitude aproveita as competências dos colaboradores em diferentes atividades, bem como aumenta o grau de satisfação. No Gráfico 3, encontram-se dados sobre o tempo que os colaboradores encontram-se desempenhando a função que exerciam no 
momento da coleta de dados.

Gráfico 3 - Tempo na Função

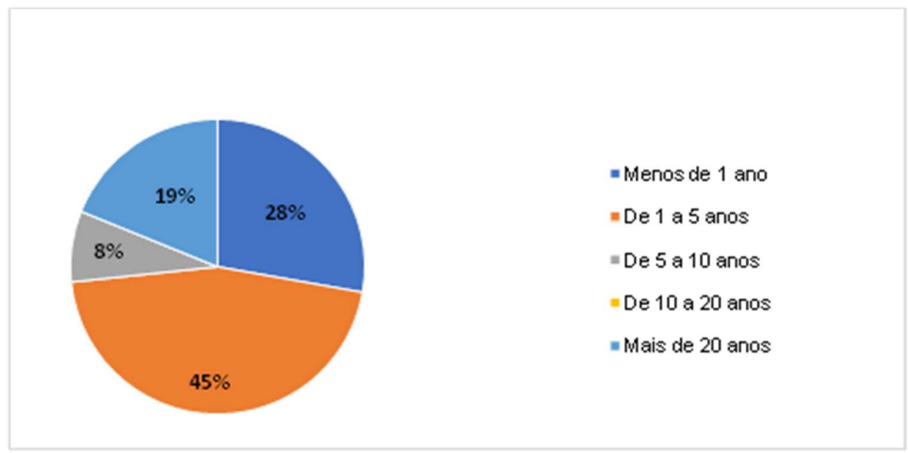

Fonte: Dados da pesquisa (2017)

Observa-se a coerência destas informações com aquelas relacionadas com o tempo de empresa e tempo na função. No que se refere aos colaboradores com mais tempo de empresa, pode-se perceber que os mesmos evoluem para funções mais complexas, o que indica que a empresa dá oportunidade de crescimento e retém seus colaboradores.

No que se refere ao grau de escolaridade dos colaboradores, prevalece o ensino médio, com 67\%; ensino médio incompleto, 9\%; graduação incompleta, 13\%; graduação completa, $8 \%$; especialização, $3 \%$. Os dados demonstram que todos os colaboradores possuem instrução, o que facilita quando se trata de resolução de conflitos e, consequentemente, instalação de um bom clima organizacional.

A partir dos dados sobre se os colaboradores possuem curso técnico para a área em que atuam na empresa, foi percebido que mais da metade o possui, sendo $67 \%$ possuidores; e $33 \%$ são os que não o possuem. Pode-se concluir que os colaboradores estão em busca de conhecimento e especialização para área que atuam, principalmente por se tratar de uma mão de obra especializada, que busca conhecimento para melhor desenvolver suas atividades. Dessa forma, esses trabalhadores também melhoram sua empregabilidade, sendo que o setor papeleiro é forte na região em que a empresa em estudo se inclui.

Questionados sobre se foi a empresa que oportunizou-lhe curso técnico, percebe-se que, para 93\% dos colaboradores, foi a empresa que ofereceu-lhe o curso; e para os outros 7\%, não o foi. Essa realidade denota a preocupação da empresa com processos de melhorias a partir das pessoas. Volta-se a destacar que a empregabilidade e crescimento individual acontece paralelamente aos benefícios que a formação de competências traz para a organização.

Sobre a renumeração dos colaboradores, $2 \%$ ganham $R \$ 800,00$ até $R \$ 1000,00 ; 42 \%$, 
de $\mathrm{R} \$ 1000,00$ a $\mathrm{R} \$ 2000,00 ; 38 \%$, de $\mathrm{R} \$ 2000,00$ até $\mathrm{R} \$ 3000,00 ; 16 \%$, de $\mathrm{R} \$ 3000,00$ a $\mathrm{R} \$$ 4000,00; e $2 \%$ ganham acima de $R \$ 4000,00$. Os colaboradores possuem plano de carreira e, conforme seu desenvolvimento, vão aumentando seu o salário, o que, de acordo com a gestora de $\mathrm{RH}$, tem motivado qual os colaboradores a sempre darem seu melhor no trabalho.

Questionados sobre se gostariam de mudar de função da empresa, 76\% dos colaboradores responderam que não querem mudar de função na empresa, que gostam do atual cargo que exercem; e $24 \%$ gostariam de mudar de função. Os que responderam que gostariam são aqueles que aguardam por uma oportunidade de crescimento. Conforme análise do Gráfico 2, são, predominantemente, os colaboradores jovens (ajudante de produção (16\%) e Operador de produção । (17\%)), os quais estão aguardando oportunidade de crescimento na empresa.

Procurou-se saber dos respondentes a respeito das técnicas utilizadas no seu processo de recrutamento ao serem admitidos na empresa. Os dados são apresentados no Gráfico 4, onde observa-se que o curriculum vitae é a técnica mais utilizada pela organização, sendo a principal forma de ingresso na empresa. Essa medida possibilita, de início, já saber informações sobre o colaborador, tornando-se uma forma eficiente de contratação.

Gráfico 4 - Processo a que foi submetido para entrar na empresa

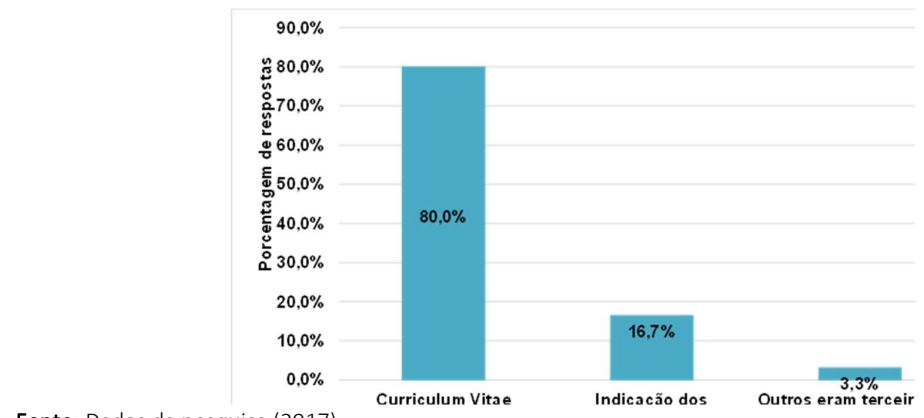

Fonte: Dados da pesquisa (2017)

Os colaboradores foram solicitados a avaliarem se o processo de recrutamento e seleção é satisfatório numa escala de ótimo a ruim. No Gráfico 5 encontram-se dados obtidos. 
Gráfico 5 - Avaliação pelos colaboradores do processo de recrutamento realizado pela empresa

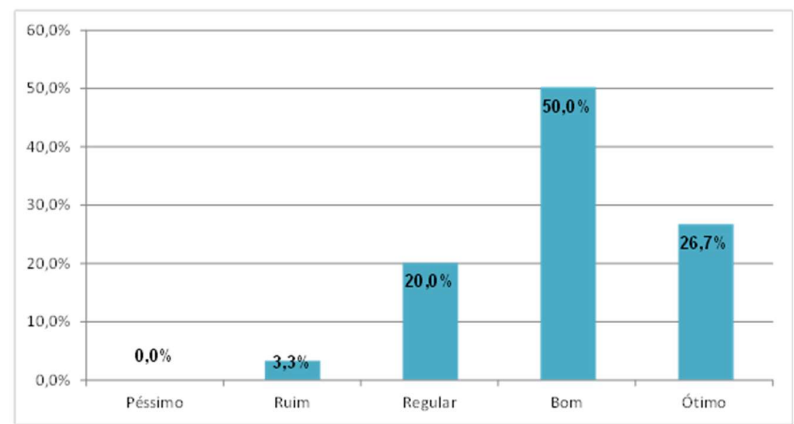

Fonte: Dados da pesquisa (2017)

Os dados revelam um alto grau de aceitação e satisfação do processo adotado pela empresa, com 76,7\%. A organização, nos últimos dois anos, de acordo com a gestora de $\mathrm{RH}$, implantou melhorias no processo de recrutamento e seleção, sendo este um método reconhecido pelos colaboradores, que identificam a organização como a que reconhece e valoriza os conhecimentos, as habilidades e as atitudes de seus colaboradores.

Com relação às técnicas de seleção, sendo que os respondentes podiam assinalar mais de uma resposta, observou-se que 100\% utilizaram a entrevista; 37,8\%, testes psicológicos; e 64,4\% passaram por testes de conhecimento e de capacidade; 1,1\% por dinâmica; 1,1\% passaram por entrevista individual.

A entrevista mostra o maior percentual (100\%), visto que é uma ferramenta que permite obter informações sobre o candidato em termos de análise comportamental. Já as provas práticas $(64,4 \%)$ e os testes psicológicos $(37,8 \%)$ proporcionam a análise de conhecimentos específicos e experiências adquiridas, tendo maior apropriação quando analisadas em conjunto.

Buscou-se, também, saber dos colaboradores da empresa se já tinham experiência profissional em outras empresas no cargo que ocupavam no momento em que responderam à pesquisa. A maioria dos respondentes, 76\%, respondeu ter experiência adquirida em outras empresas; $24 \%$ declararam não possuir experiência anterior. Conclui-se que a empresa também abre portas para colaboradores sem experiência, principalmente os mais jovens, que estão ingressando no mercado de trabalho e precisam dessa inserção. Assim, a empresa ganha, pois pode treinar o colaborador de acordo com suas políticas e diretrizes; e o jovem adquire experiência.

No Quadro 2 é apresentado o nível de satisfação dos colaboradores quanto ao cargo que ocupam na organização, onde percebe-se que há um bom índice de satisfação $(87,77 \%)$ quando de trata de avaliar o quanto as pessoas sentem que empregam suas competências e, 
portanto, sentem que o que fazem é importante no processo de produção como um todo.

Quadro 2 - Nível de satisfação sobre o trabalho

\begin{tabular}{|l|l|l|l|l|l|}
\hline & Ótimo & Bom & Regular & Ruim & Péssimo \\
\hline $\begin{array}{l}\text { O cargo } \\
\text { permite utilizar } \\
\text { suas } \\
\text { competências } \\
\text { profissionais }\end{array}$ & $27,77 \%$ & $60 \%$ & $12,22 \%$ & $0 \%$ & $0 \%$ \\
\hline $\begin{array}{l}\text { Média da } \\
\text { percepção dos } \\
\text { colaboradores }\end{array}$ & $\begin{array}{l}\text { Satisfação } \\
87,77 \%\end{array}$ & $\begin{array}{l}\text { Neutro } \\
12,22 \%\end{array}$ & $\begin{array}{l}\text { Insatisfação } \\
0 \%\end{array}$ \\
\hline
\end{tabular}

Fonte: Dados da pesquisa (2017)

O Quadro 3 contém dados sobre avaliação do nível de satisfação com o modelo de gestão adotado pela empresa, ponto que também há predomínio de satisfação $(86,66 \%)$ com o modelo de gestão da empresa. No momento da contratação e integração são repassadas diretrizes, políticas e práticas adotadas pela empresa, as quais, ainda assim, podem não ficar claras a alguns, que, provavelmente, compõem os que avaliam o modelo como regular $(12,22 \%$ ou ruim $(1,11 \%)$.

Quadro 3 - Avaliação do Modelo de gestão

\begin{tabular}{|l|l|l|l|l|l|}
\hline & Ótimo & Bom & Regular & Ruim & Péssimo \\
\hline $\begin{array}{l}\text { Modelo de gestão de pessoas } \\
\text { (contratação, integração, treinamento e } \\
\text { benefício) }\end{array}$ & $26,66 \%$ & $60 \%$ & $12,22 \%$ & $1,11 \%$ & $0 \%$ \\
\hline Percepção dos colaboradores & $\begin{array}{l}\text { Satisfação } \\
86,66 \%\end{array}$ & $\begin{array}{l}\text { Neutro } \\
12,22 \%\end{array}$ & $\begin{array}{l}\text { Insatisfação } \\
1,11 \%\end{array}$ \\
\hline
\end{tabular}

Fonte: Dados da pesquisa (2017)

Os dados constantes no Quadro 4 mostram que a empresa mantém seus colaboradores predominantemente satisfeitos $(88,87 \%)$ e que eles se sentem realizados profissional e pessoalmente por fazerem parte da organização. 
Quadro 4 - Nível de satisfação pessoal e profissional

\begin{tabular}{|l|l|l|l|l|l|}
\hline & Ótimo & Bom & Regular & Ruim & Péssimo \\
\hline $\begin{array}{l}\text { Realização PROFISSIONAL por trabalhar na } \\
\text { empresa. }\end{array}$ & $37,77 \%$ & $47,77 \%$ & $12,22 \%$ & $2,22 \%$ & $0 \%$ \\
\hline $\begin{array}{l}\text { Realização PESSOAL por trabalhar na } \\
\text { empresa. }\end{array}$ & $45,55 \%$ & $46,66 \%$ & $7,77 \%$ & $0 \%$ & $0 \%$ \\
\hline Total das respostas & $83,32 \%$ & $94,43 \%$ & $19,99 \%$ & $2,22 \%$ & $0 \%$ \\
\hline Média das respostas & $41,66 \%$ & $47,21 \%$ & $9,99 \%$ & $1,11 \%$ & $0 \%$ \\
\hline Total da percepção dos colaboradores & $\begin{array}{l}\text { Satisfaç̃ão } \\
88,87 \%\end{array}$ & $\begin{array}{l}\text { Neutro } \\
9,99 \%\end{array}$ & $\begin{array}{l}\text { Insatisfação } \\
1,11 \%\end{array}$ \\
\hline
\end{tabular}

Fonte: Dados da pesquisa (2017)

Tais percepções asseguram a confiabilidade dos colaboradores tanto profissional como pessoal, comprovando que a metodologia utilizada favorece o crescimento e reconhecimento dos colaboradores.

No Quadro 5 encontram-se dados sobre a avaliação do treinamento realizado pelos colaboradores ao ingressar na organização e sobre o nível de informação que lhes é repassado quando são contratados.

Quadro 5 - Nível de satisfação da integração e informação sobre direitos e benefícios

\begin{tabular}{|l|l|l|l|l|l|}
\hline & Ótimo & Bom & Regular & Ruim & Péssimo \\
\hline $\begin{array}{l}\text { Processo de TIB (treinamento de } \\
\text { integração básico)? }\end{array}$ & $15,55 \%$ & $68,88 \%$ & $12,22 \%$ & $3,33 \%$ & $0 \%$ \\
\hline $\begin{array}{l}\text { Informações sobre direitos e deveres, } \\
\text { benefícios e plano de carreira. }\end{array}$ & $33,33 \%$ & $55,55 \%$ & $8,88 \%$ & $2,22 \%$ & $0 \%$ \\
\hline Total das respostas & $48,88 \%$ & $124,43 \%$ & $21,1 \%$ & $5,55 \%$ & $0 \%$ \\
\hline Média das respostas & $24,44 \%$ & $62,21 \%$ & $10,55 \%$ & $2,77 \%$ & $0 \%$ \\
\hline Total da percepção dos colaboradores & $\begin{array}{l}\text { Satisfação } \\
86,65 \%\end{array}$ & $\begin{array}{l}\text { Neutro } \\
10,55 \%\end{array}$ & $\begin{array}{l}\text { Insatisfação } \\
2,77 \%\end{array}$ \\
\hline
\end{tabular}

Fonte: Dados da pesquisa (2017)

As respostas dos colaboradores confirmam o que a gestora de $\mathrm{RH}$ da empresa informou sobre que procuram passar transparência a respeito de benefícios, deveres e plano de carreira, bem como o processo de integração e os treinamentos oferecidos, mantendo os colaboradores conectados às políticas da organização, com clareza.

O Quadro 6 contém dados sobre o nível em que os colaboradores sentem segurança quanto a se manterem no emprego na empresa. 
Quadro 6 - Nível de segurança no emprego

\begin{tabular}{|l|l|l|l|l|l|}
\hline & Ótimo & Bom & Regular & Ruim & Péssimo \\
\hline Garantia de emprego no cargo & $22,22 \%$ & $63,33 \%$ & $13,33 \%$ & $1,11 \%$ & $0 \%$ \\
\hline Total da percepção dos colaboradores & $\begin{array}{l}\text { Satisfação } \\
85,55 \%\end{array}$ & $\begin{array}{l}\text { Neutro } \\
13,33 \%\end{array}$ & $\begin{array}{l}\text { Insatisfação } \\
1,11 \%\end{array}$ \\
\hline
\end{tabular}

Fonte: Dados da pesquisa (2017)

Predominantemente $(85,55 \%)$, a empresa passa segurança aos colaboradores quanto à garantia que eles têm no emprego. Além de proporcionar segurança, retém seus colaboradores. A retenção de talentos, segundo a gestora, faz parte das políticas e práticas adotadas no processo, visando o melhor desenvolvimento pessoal e crescimento da organização.

Quanto à avaliação dos treinamentos recebidos para realizar seu trabalho, a maioria dos colaboradores respondeu positivamente $(88,88 \%)$ sobre os treinamentos que recebem para melhorar suas competências e qualificações; $8,88 \%$ avaliam como regular; e apenas $2,22 \%$, encontram-se insatisfeitos. Para a organização, é de suma importância a oportunidade que disponibiliza aos colaboradores para que recebam treinamento, visando melhor desempenho nas atividades. Essa política gera, para os colaboradores, a garantia de que permanecerão e de que têm oportunidade de crescimento.

Realizou-se, ainda, uma pergunta aberta para que os colaboradores expressassem críticas ou sugestões ao processo de recrutamento e seleção da empresa. Dos respondentes, $57,77 \%$ preferiram não responder; $10 \%$ responderam não ter sugestão nem crítica sobre o processo; $12,22 \%$ relatam que o processo está ótimo; $1,11 \%$ deixam como sugestão a aplicação de mais treinamento aos colaboradores após a contratação.

Os demais $18,88 \%$ relatam que o processo melhorou muito nos últimos dois anos. Há quem afirme que a organização está de parabéns, e há os que dão algumas sugestões, como a de participação maior das pessoas responsáveis pelo setor, que precisa rever os conceitos de avaliação de provas para os cargos, ter mais transparência no processo em pontos em que se avalia o colaborador para entrar na empresa.

Também se sugere que, antes de mudar pessoas ou maquinários, que se ouçam os colaboradores. Afirmam que a empresa deve olhar para quem está há mais tempo na empresa e que possui experiência. Sugere-se idade mínima para entrar na empresa, porque há funcionários muito novos e com pouca experiência, com algumas atitudes não muito condizentes, de acordo com suas opiniões.

Os colaboradores observam ainda que é preciso levar em consideração a experiência para algumas funções, pois estas podem ser determinantes para o sucesso do processo produtivo, bem como para a motivação dos funcionários no que se refere a investir em cursos, 
formações, especializações. Outra sugestão é em relação a um profissional de psicologia avaliar uma pessoa no dia da entrevista, sendo que a pessoa pode não estar num bom dia, isso, na visão deles, não é certo.

Atualmente o setor da pesquisa conta com três supervisores, estes foram questionados sobre como avaliam o processo de recrutamento e seleção. Eles ressaltam que é um processo justo, que oportuniza o crescimento e desenvolvimento dos colaboradores, pois avalia o perfil de acordo com a vaga.

Sobre se os candidatos superam as expectativas esperadas para o cargo, dizem que não existe grande oferta de mão de obra e que, geralmente, é acertada a escolha do candidato, mas esporadicamente acontece de contratar pessoas com perfil aquém das necessidades. Dizem que, durante a dinâmica de que eles participam, percebe-se claramente a capacidade de interação dos candidatos, porém, para algumas vagas ainda há falta de preparo de alguns no que se refere ao perfil que se busca, que é o da proatividade, iniciativa etc.

Quando questionados sobre o retorno que têm quando abre uma vaga, ficou claro que sempre recebem rápido feedback do $\mathrm{RH}$. Sobre dicas de melhorias, os mesmos dizem que não as têm, que o processo deve se manter até que surjam necessidades de mudança. Apenas que, quando acontece o recrutamento interno, deve-se avaliar com mais acuracidade aqueles que estão há mais tempo na empresa.

Os supervisores afirmam que buscam cativar e envolver os colaboradores para que notem a importância do seu trabalho no processo como um todo. Dizem que tudo que aprenderam foi durante a experiência na carreira, o que os leva a aplicarem as técnicas de gestão no dia a dia, tornando-se mais assertivos nas decisões.

Os supervisores avaliam que o processo acontece de maneira transparente e que, quando se consegue atender os requisitos necessários, a empresa tem um colaborador realizado profissionalmente, dando sempre o seu melhor, sendo esse o melhor caminho. Os que estão há mais tempo na empresa, enfatizam que o processo de recrutamento e seleção nunca esteve tão eficiente e que, com ajustes pontuais sempre que seja necessário, deve manter a excelência.

Assim, é possível tecer considerações sobre os processos utilizados pela empresa em estudo para recrutar e selecionar pessoas. As respostas obtidas permitem observar que os colaboradores identificam com clareza os critérios que precisam cumprir para ocupar um posto e os propósitos da empresa no sentido de recrutar e selecionar pessoas. Além disso, verificase que consideram o que aprendem como positivo e favorável para a sua carreira profissional.

A empresa adota uma prática que não apenas retém talentos, mas que se preocupa em ajustar-se à realidade. Assim, os colaboradores possuem crescimento na sua função, de ajudante operacional a operador em escala de I a V. Durante a pesquisa, percebeu-se um bom clima organizacional, em que os colaboradores trabalham, reconhecendo oportunidades de 
crescimento e desenvolvimento ofertados pela empresa.

Percebe-se, com a pesquisa, que o processo utilizado pela empresa proporciona resultados positivos. Considera-se o $\mathrm{RH}$ como o canal de comunicação e meio de interação entre as áreas estratégicas e operacionais da empresa. Além disso, a empresa tem baixo índice de rotatividade. Observa-se que existe gestão participativa na tomada de decisões no setor de $\mathrm{RH}$.

Durante a pesquisa, os colaboradores com mais tempo de empresa acompanharam o crescimento da organização desde maquinário à parte de gestão. Estes comentaram que o processo mudou muito com o avanço tecnológico. Foram implantadas novas máquinas e disponibilizados cursos para os colaboradores conduzirem as mesmas. Isso motiva os colaboradores, que se sentem prestigiados pelo que fazem, reiterando a eficiência do processo que se emprega na empresa.

\section{CONCLUSÃO}

A partir da proposta de pesquisa desse artigo apresentam-se as conclusões a que se chegou ao analisar as percepções e satisfação dos colaboradores sobre o processo de recrutamento e seleção adotados pela empresa em estudo.

As diretrizes e ferramentas do processo de recrutamento e seleção adotados pela empresa são fundamentais para que todos compreendam e acompanhem as etapas do processo que se inicia quando uma vaga é aberta em um posto de trabalho. Chega-se à conclusão de que a prática adotada pela organização é estratégica e estruturada, visando melhorias no processo de recrutamento e seleção, que visa o crescimento da organização e satisfação de pessoal.

Ao avaliar o nível de conhecimento e as percepções dos colaboradores sobre o processo de recrutamento e seleção, chegou-se à conclusão de que os colaboradores, predominantemente, reconhecem e aprovam o modelo adotado pela empresa, e que os supervisores acompanham o trabalho da área de recursos humanos.

Quanto ao nível de excelência dos métodos utilizados pela empresa para recrutar e selecionar pessoas, conclui-se que o método tem resultado positivo certificando-se como um modelo de eficiência e eficácia. A análise dos dados permitiu afirmar que a empresa se preocupa com as pessoas e que mantém estratégias para reter talentos na organização. As técnicas de recrutamento e seleção adotados são bem-sucedidas.

Para a empresa, essa pesquisa apontou resultados de suma importância, pois se tratou de um trabalho de avaliação do modelo que a empresa adota para recrutar e selecionar pessoas, dando a oportunidade de a empresa conhecer a opinião de seus colaboradores sobre esse processo. Ao entrar em contato com os colaboradores, percebeu-se a intenção de alguns 
deles em cursos técnicos. Sugere-se então que sejam feitas pesquisas nessa direção, que definam as necessidades das empresas e que instituições de ensino poderiam oferecer os referidos cursos.

Embora esse estudo tenha atingido seu objetivo, destacam-se alguns fatores limitantes constatados durante a produção da pesquisa. Inicialmente, percebeu-se que o fator tempo impossibilitou melhor planejamento e desenvolvimento do trabalho de coleta de dados. Outro fator limitante foram os resultados afetados pelo número de respondentes à pesquisa. $O$ ideal seria que houvesse um tempo maior para a coleta de dados e fosse feito com todos os 500 colaboradores da empresa.

\section{REFERÊNCIAS}

BOHLANDER George; SNELL, Scott. Administração de Recursos Humanos. 13.ed. Tradução da 14.ed. norte-americana. São Paulo: Cengage Learning, 2010.

FLEURY, Afonso; FLEURY Maria Tereza Leme. Estratégias empresariais e formação de competências. 3. ed. São Paulo: Atlas, 2013.

GIL, Antônio Carlos. Gestão de pessoas: enfoque nos papéis profissionais. São Paulo: Atlas, 2014.

GRAMIGNA, Maria Rita. Modelo de competências e gestão de talentos. São Paulo: Makron Books, 2002.

MARCONI, Marlene; LAKATOS, Eva Maria. Técnicas de pesquisa: planejamento e execução de pesquisas, amostragem técnicas de pesquisas, elaboração, análise e interpretação de dados. 7. ed. São Paulo: Atlas, 2011.

MARRAS, Jean Pierre. Administração de recursos humanos: do operacional ao estratégico. São Paulo: Futura, 2002.

PONTES, Benedito Rodrigues. Planejamento, recrutamento e seleção de pessoal. 4. ed. São Paulo: LTr, 2004.

RIBEIRO, Antônio L. Gestão de pessoas. São Paulo: Saraiva, 2005.

SOUSA, et al. Gestão de recursos humanos: métodos e práticas. Lisboa: Lidel, 2014.

TACHIZAWA Takeshy; FERREIRA, Victor C.P; FORTUNA, Antônio A.M. Gestão de pessoas: uma abordagem aplicada às estratégias de negócios. 2. ed. Rio de Janeiro: FGV, 2001.

TROMBINI. A Trombini. Disponível em: http://www.trombini.com.br/a-trombini/ Acesso em 14 fev. 2018.

WERTHER, W.; DAVIS, K. Administração de pessoal e recursos humanos. São Paulo: McGraw 
Hill, 1983. 